\title{
High Strength-Ductility Nb-microalloyed Low Martensitic Carbon Steel: Novel Process and Mechanism
}

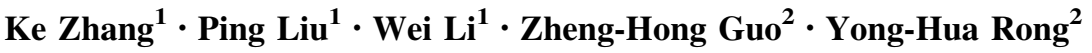

Received: 3 August 2015/Revised: 16 September 2015/Published online: 12 October 2015

(C) The Chinese Society for Metals and Springer-Verlag Berlin Heidelberg 2015

\begin{abstract}
A low-carbon $\mathrm{Nb}$-microalloyed $\mathrm{Fe}-\mathrm{Mn}$-Si-based steel was treated by a novel quenching-partitioning-tempering $(\mathrm{Q}-\mathrm{P}-\mathrm{T})$ process as a modified quenching and partitioning $(\mathrm{Q} \& \mathrm{P})$ process. After processed by $\mathrm{Q}-\mathrm{P}-\mathrm{T}$ treatment, this steel exhibits excellent mechanical properties such as high product of strength and elongation. The addition of $\mathrm{Nb}$ markedly raises both the yield strength and tensile strength of Q-P-T martensitic steel, especially the yield strength, which can be attributed to the strong grain refinement strengthening and precipitation strengthening of $\mathrm{Nb}$. The $\mathrm{Nb}$ addition can also lead to a little increase in ductility. The Nb-microalloyed steel treated by $\mathrm{Q}-\mathrm{P}-\mathrm{T}$ process displays much higher ductility than that treated by traditional quenching and tempering (Q\&T) process. The mechanisms of Q-P-T process on ductility enhancement were fully analyzed and can be attributed to high quenching temperature and considerable amount of retained austenite.
\end{abstract}

KEY WORDS: Heat treatment; Mechanical properties; Microstructure; Microalloyed steel; Martensitic transformation

\section{Introduction}

In the past decade, more and more advanced high-strength steels (AHSS) are being used in the automotive industry for reducing vehicle weight and increasing fuel efficiency without sacrificing passenger safety [1]. The development of AHSS is focused on high strength together with sufficient ductility. Therefore, several kinds of low-alloying Fe-Mn-Si-based AHSS have been studied intensively, such as dual-phase (DP) steels consisting of ferrite and

Available online at http://link.springer.com/journal/40195

Ke Zhang

zhangke@usst.edu.cn

1 School of Materials Science and Engineering, University of Shanghai for Science and Technology, Shanghai 200093, China

2 School of Materials Science and Engineering, Shanghai Jiao Tong University, Shanghai 200240, China martensite [2] and transformation-induced plasticity (TRIP) steels consisting of ferrite, bainite and retained austenite [3, 4], quenching and partitioning (Q\&P) steels consisting of martensite and retained austenite [5-9] as well as quenching-partitioning-tempering (Q-P-T) steels consisting of martensite, retained austenite and carbide [10]. In AHSS, Q\&P steels and Q-P-T steels show the highest strength and enough ductility because the martensite matrix has higher strength than ferrite matrix in DP or TRIP steels; meanwhile, considerable amount of retained austenite plays an important role in ductility enhancement. Speer et al. [5] proposed novel Q\&P process in 2003, where a Si-containing steel was subjected to quenching from austenitizing temperature to a temperature $\left(T_{\mathrm{q}}\right)$ between the martensite-start $\left(M_{\mathrm{s}}\right)$ temperature and martensite-finish $\left(M_{\mathrm{f}}\right)$ temperature, followed by a "partitioning" treatment either at (one-step Q\&P) or above (twostep Q\&P) $T_{\mathrm{q}}$ temperature. During "partitioning," the carbon diffuses from the supersaturated martensite phase to the untransformed austenite phase, and thus carbon- 
enriched retained austenite can be stabilized in subsequent cooling to room temperature. For low- or medium-carbon Q\&P steels, the quenching temperature $T_{\mathrm{q}}$ is usually much higher than room temperature [5], and thus considerable retained austenite can be obtained. Based on Q\&P process and constrained carbon paraequilibrium (CCE) theory, Hsu [10] proposed the Q-P-T process in 2007. Additional carbide-forming elements such as $\mathrm{Nb}$ and $\mathrm{Mo}$ are added into Q-P-T steels, which are not permitted in CCE theory of Q\&P process, and the addition of these elements leads to carbides formation and grain refinement for precipitation and grain refinement strengthening [11]. Since the Q-P-T process contains the essentials of $\mathrm{Q} \& \mathrm{P}$ process: quenching temperature $\left(T_{\mathrm{q}}\right)$ determined by combination of CCE theory and Koistinen-Marburger (K-M) equation [12], the Q$\mathrm{P}-\mathrm{T}$ martensitic steels also have considerable retained austenite comparing with traditional quenching and tempering (Q\&T) steels (where $T_{\mathrm{q}}$ is room temperature in $\mathrm{Q} \& \mathrm{~T}$ process). In investigating the first $\mathrm{Q}-\mathrm{P}-\mathrm{T}$ steel, the precipitation strengthening of $\mathrm{Nb}$ by tempering was determined as $130 \mathrm{MPa}$ [13]. Although this medium-carbon steel treated by Q-P-T process exhibits the tensile strength of high up to $2000 \mathrm{MPa}$, high $\mathrm{Nb}$ content $(0.2 \mathrm{wt} \%)$ results in poor ductility of about $10 \%$, and the product of strength and elongation (PSE) is only about $20 \mathrm{GPa} \%$ [13]. After that, high strength-ductility mediumcarbon Q-P-T steel with over $30 \mathrm{GPa} \%$ [14] and lowcarbon Q-P-T steel with over $20 \mathrm{GPa} \%$ [15] were developed. In developing high strength-ductility Q-P-T steels, the effect of retained austenite on ductility enhancement was focused and studied. Zackay et al. [16] proposed TRIP effect in 1967, where the strain-induced martensitic transformation from retained austenite relaxes the stress concentration and redistributes the stresses during plastic deformation and thus delays the necking till the high strain region [17]. The occurrence of TRIP effect in Q-P-T was verified by experiments. For the effect of retained austenite on the toughness of high-strength steels, Webster proposed that the retained austenite blocking crack propagation (BCP) in 1968 [18], i.e., the cracks either propagate continuously in the austenite or trace a zigzag path through interlocking martensite laths, both of which will require an increased energy for fracture. The thin austenite layers between martensite laths could reduce the stress concentration at the crack tip and improve the fracture toughness $[19,20]$. Recently, we found a new effect of retained austenite on ductility enhancement in studying the medium-carbon Q-P-T martensitic steel. Based on the measurement of average dislocation densities in both martensite and retained austenite by using X-ray diffraction line profile analysis (XLPA) [21], a named DARA (dislocation absorption by retained austenite) effect has been proposed, i.e., dislocations in martensite move into nearby retained austenite through martensite-retained austenite interfaces, and these dislocations are absorbed by retained austenite during the deformation process. The possibility of dislocations transmitted from bcc-phase into the fcc-phase has been verified by molecular dynamic simulations in $\mathrm{Cu}-$ $\mathrm{Nb}$ bi-layered film [22]. DARA effect makes hard phase, martensite, be a "softening" state during the deformation and thus effectively enhances the deformation ability of martensite matrix. Two empirical conditions for remarkable DARA effect were further proposed [23]: (1) enough amount of retained austenite, larger than $10 \%$ in volume fraction; (2) coherent or semi-coherent interface between two phases. These two conditions were confirmed by lowcarbon Q-P-T steel [21], bainitic steel [24] and high-carbon Q-P-T steel [25], respectively, where the coherent or semi-coherent interface between martensite (or bainite) and retained austenite shows either $\mathrm{K}-\mathrm{S}$ or $\mathrm{N}-\mathrm{W}$ orientation relationship. Besides, the dynamic compression behavior [26] and the elevated temperature properties of low-carbon Q-P-T steel with addition of $\mathrm{Nb}$ element [27] were further investigated for extending their possible application in engineering.

So far, there are still three issues to be solved in the study of Q-P-T steels: (1) Does the strengthening effect of $\mathrm{Nb}$ stem mainly from precipitation or grain refinement strengthening? (2) Does the addition of $\mathrm{Nb}$ certainly result in the loss of ductility? (3) Why novel Q-P-T process can markedly enhance ductility? In this study, therefore, two kinds of steels ( $\mathrm{Nb}$-microalloyed and $\mathrm{Nb}$-free) were designed and treated by the Q-P-T, Q\&P and Q\&T processes, respectively. The above issues will be further explored by characterization of their mechanical properties and microstructures.

\section{Experimental}

Two kinds of low-carbon steels containing $\mathrm{Nb}$ or not are abbreviated as $\mathrm{Nb03}$ and $\mathrm{Nb00}$, respectively, and their chemical compositions are listed in Table 1 where their $A c_{3}, M_{\mathrm{s}}$ and $M_{\mathrm{f}}$ temperatures are included measured by a Formaster FII dilatometer. The composition design for the two kinds of steels is based on the following aspects. The addition of $\mathrm{Mn}$ is to stabilize retained austenite and provides adequate hardenability, while the addition of $\mathrm{Si}$ is to inhibit the formation of brittle $\mathrm{Fe}_{3} \mathrm{C}$ Carbide. The addition of $0.03 \mathrm{wt} \% \mathrm{Nb}$ to $\mathrm{Nb03}$ steel was used to further raise strength by precipitation and grain refinement strengthening. The designed steels were melted in a laboratory medium frequency furnace and hot-rolled to a slab of $12 \mathrm{~mm}$ thickness. The samples of $2 \mathrm{~mm}$ in thickness were cut from a hot-rolled plate and then were treated by Q-P$\mathrm{T}, \mathrm{Q} \& \mathrm{~T}$ and Q\&P processes, respectively. Three different 
Table 1 Chemical compositions of experimental steels (in wt pct)

\begin{tabular}{llllllll}
\hline Steel & $\mathrm{C}$ & $\mathrm{Mn}$ & $\mathrm{Si}$ & $\mathrm{Nb}$ & $\mathrm{Fe}$ & $A \mathrm{c}_{3}\left({ }^{\circ} \mathrm{C}\right)$ & $M_{\mathrm{s}}\left({ }^{\circ} \mathrm{C}\right)$ \\
\hline $\mathrm{Nb00}$ & 0.2 & 1.54 & 1.58 & - & Bal. & $904 \pm 5$ & $415 \pm 5$ \\
$\mathrm{Nb03}$ & 0.19 & 1.52 & 1.57 & 0.029 & $\mathrm{Bal}$ & $911 \pm 5$ & $395 \pm 5$ \\
\hline
\end{tabular}

heat treatment processes are schematically shown in Fig. 1. The samples were austenitized at $940{ }^{\circ} \mathrm{C}$ for $300 \mathrm{~s}$, followed by quenching into salt bath at $300{ }^{\circ} \mathrm{C}$ for $15 \mathrm{~s}$ and subsequent partitioning/tempering at $450{ }^{\circ} \mathrm{C}$ for $30 \mathrm{~s}$ in molten salt, and finally quick quenching into water. The above quenching temperature $\left(300^{\circ} \mathrm{C}\right)$ was determined based on $\mathrm{CCE}$ theory/K-M equation after a slight modification. The above process is called $\mathrm{Q}-\mathrm{P}-\mathrm{T}$ process for $\mathrm{Nb}$ microalloyed samples, and $\mathrm{Q} \& \mathrm{P}$ process for $\mathrm{Nb}$-free samples. For Q\&T process, the $\mathrm{Nb00}$ steel and $\mathrm{Nb03}$ samples were austenitized at $940{ }^{\circ} \mathrm{C}$ for $300 \mathrm{~s}$, followed by water quenching to room temperature, then tempering at $450{ }^{\circ} \mathrm{C}$ for $30 \mathrm{~s}$ in molten salt. The difference between Q-P-T (or $\mathrm{Q} \& \mathrm{P})$ process and $\mathrm{Q} \& \mathrm{~T}$ process just lies in quenching temperature $\left(T_{\mathrm{q}}\right)$, and $T_{\mathrm{q}}$ is room temperature in $\mathrm{Q} \& \mathrm{~T}$ process.

The samples for tensile test were prepared with a gauge length of $15 \mathrm{~mm}$ and width of $5 \mathrm{~mm}$. Tensile tests were carried out on a Zwick T1-FR020TN A50 testing machine with a strain rate of $10^{-3} / \mathrm{s}$ at room temperature. The tensile axis was parallel to the rolling direction. The fracture morphologies were observed on a JSM-6460 scanning electron microscope (SEM). The microstructure of the specimens was further characterized by transmission electron microscopy (TEM, JEM-2100F, $200 \mathrm{kV}$ ) after electropolishing by a twin-jet polisher in $4 \%$ perchloric acid

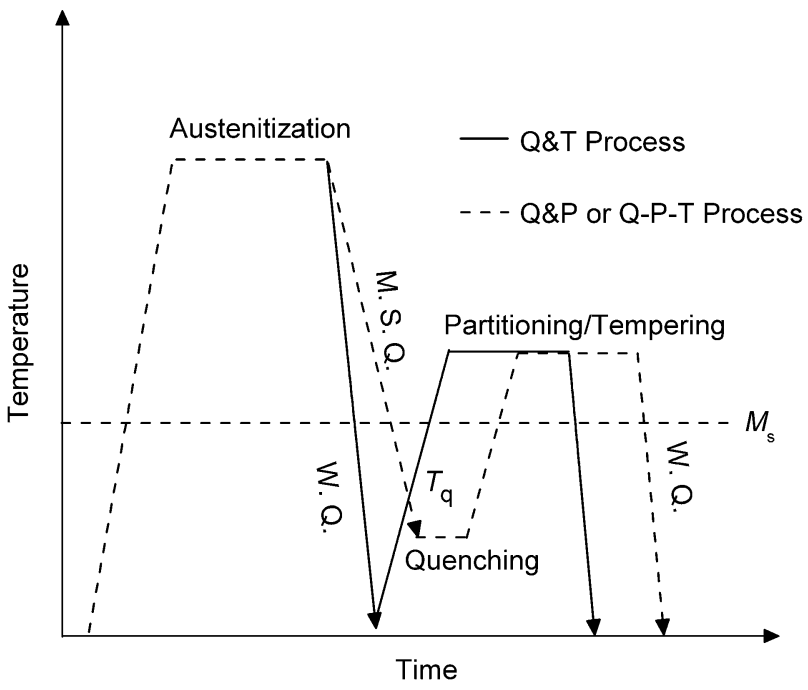

Fig. 1 Schematic heat treatment diagram of the $Q-P-T, Q \& P$ and $Q \& T$ processes, where the abbreviation of M.S.Q. and W.Q. represent molten salt quenching and water quenching, respectively and $96 \%$ ethanol solution at $-20{ }^{\circ} \mathrm{C}$. The volume fraction of retained austenite was determined by X-ray diffraction (XRD) with $\mathrm{Cu} K_{\alpha}$ radiation in a $\mathrm{D} / \max -2550 \mathrm{X}$-ray diffractometer on the basis of direct comparison of integrated intensity of the austenite peaks $(200)_{\gamma},(220)_{\gamma}$ and (311) $\gamma$ with martensite peaks $(200)_{\alpha}$ and $(211)_{\alpha}$.

\section{Results}

The tensile curves of the two kinds of low-carbon steels treated, respectively, by $\mathrm{Q}-\mathrm{P}-\mathrm{T}, \mathrm{Q} \& \mathrm{P}$ and $\mathrm{Q} \& \mathrm{~T}$ processes are shown in Fig. 2. Table 2 lists the mechanical properties of the specimens treated by Q-P-T, Q\&P and Q\&T processes, including yield strength $\left(\sigma_{0.2}\right)$, tensile strength $\left(\sigma_{\mathrm{b}}\right)$, uniform elongation $\left(\delta_{\mathrm{u}}\right)$ and total elongation $\left(\delta_{\mathrm{b}}\right)$, as well as $\operatorname{PSE}\left(\sigma_{\mathrm{b}} \times \delta_{\mathrm{b}}\right)$. The results indicate that the strength of $\mathrm{Nb}$ microalloyed steels is always higher than that of $\mathrm{Nb}$-free steel, especially the yield strength. For example, the $\sigma_{0.2}$ and $\sigma_{\mathrm{b}}$ of Nb03 Q\&T sample are 1227 and $1337 \mathrm{MPa}$, respectively, which are higher than 1149 and $1266 \mathrm{MPa}$ for Nb00 Q\&T sample, respectively. For the same process of Q-P-T and Q\&P, the $\sigma_{0.2}$ and $\sigma_{\mathrm{b}}$ of Nb03 Q-P-T sample are 1146 and $1247 \mathrm{MPa}$, respectively, which are also higher than 1094 and $1236 \mathrm{MPa}$ of Nb00 Q\&P sample, respectively. Besides, the elongation of $\mathrm{Nb03}$ sample is slightly higher that of $\mathrm{Nb00}$ sample, e.g., the $\delta_{\mathrm{u}}$ and $\delta_{\mathrm{b}}$ of $\mathrm{Nb03}$ Q\&T sample are 4.0 and $12.2 \%$, respectively,

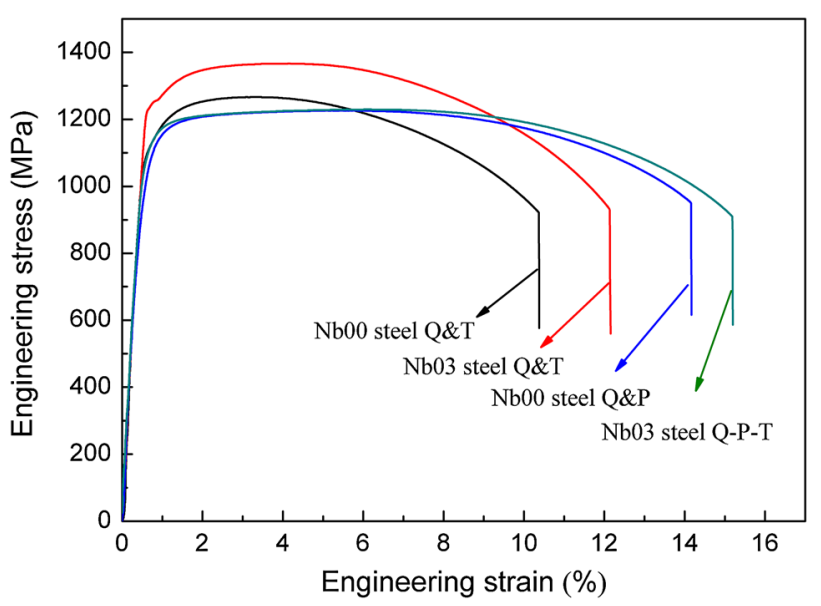

Fig. 2 Tensile engineering stress and strain curves of the $\mathrm{Nb00}$ steel and $\mathrm{Nb} 03$ steel treated by $Q-P-T, Q \& P$ and $Q \& T$ processes 
Table 2 Mechanical properties of the steels treated by Q\&T, Q\&P and Q-P-T processes

\begin{tabular}{lllllll}
\hline Steel & Process & $\sigma_{0.2}(\mathrm{MPa})$ & $\sigma_{\mathrm{b}}(\mathrm{MPa})$ & $\delta_{\mathrm{u}}(\%)$ & $\delta_{\mathrm{b}}(\%)$ & $11.7 \pm 0.8$ \\
\hline $\mathrm{Nb00}$ & Q\&T & $1149 \pm 7$ & $1266 \pm 9$ & $3.8 \pm 0.3$ & $\sigma_{\mathrm{b}} \times \delta_{\mathrm{b}}(\mathrm{GPa} \%)$ \\
$\mathrm{Nb03}$ & Q\&T & $1227 \pm 13$ & $1337 \pm 14$ & $4.0 \pm 0.1$ & $12.2 \pm 0.5$ & 14.8 \\
$\mathrm{Nb00}$ & Q\&P & $1094 \pm 17$ & $1236 \pm 9$ & $5.4 \pm 0.8$ & $13.9 \pm 0.8$ & 17.2 \\
$\mathrm{Nb03}$ & Q-P-T & $1146 \pm 15$ & $1247 \pm 15$ & $6.0 \pm 0.3$ & $15.0 \pm 0.5$ & 18.7 \\
\hline
\end{tabular}

slightly higher than 3.8 and $11.7 \%$ of Nb00 Q\&T sample, while for the Nb03 Q-P-T sample, the values of $\delta_{\mathrm{u}}$ and $\delta_{\mathrm{b}}$ are 6.0 and $15.0 \%$, respectively, slightly higher than 5.4 and $13.9 \%$ for Nb00 Q\&P sample. Therefore, Q-P-T steel exhibits the highest PSE (18.7 GPa\%), the second Q\&P steel (17.2 GPa\%), the third Nb-microalloyed Q\&T steel (16.3 GPa\%) and finally the $\mathrm{Nb}$-free Q\&T steel (14.8 GPa\%). The PSE (energy unit), as a comprehensive property, is traditionally considered to represent the properties of toughness [28].

Figure 3 shows the XRD spectra of $\mathrm{Nb00}$ and $\mathrm{Nb03}$ samples treated by $\mathrm{Q} \& \mathrm{~T}, \mathrm{Q} \& \mathrm{P}$ and $\mathrm{Q}-\mathrm{P}-\mathrm{T}$ processes, respectively. It is clear that only bcc-phase appears in the Q\&T samples, indicating no fcc-phase peak, while the diffraction peaks of fcc-phase are clearly visible in both $\mathrm{Q} \& \mathrm{P}(\mathrm{Nb00)}$ and $\mathrm{Q}-\mathrm{P}-\mathrm{T}(\mathrm{Nb03})$ samples in addition to strong diffraction peaks of bcc-phase. And the fractions of fcc-phase are determined to be 5.5 vol\% for Q\&P (Nb00) sample and 6.8 vol\% for Q-P-T (Nb03) sample, respectively. The TEM observation for the Nb00 Q\&T and Q\&P specimens (Fig. 4) further reveals that the bcc-phase is dislocation-type martensite and the fcc-phase is retained austenite. Moreover, the film-like retained austenite distributes between the martensite laths, which are verified by bright-field (BF) images (Fig. 4a, c) and the dark-field (DF)

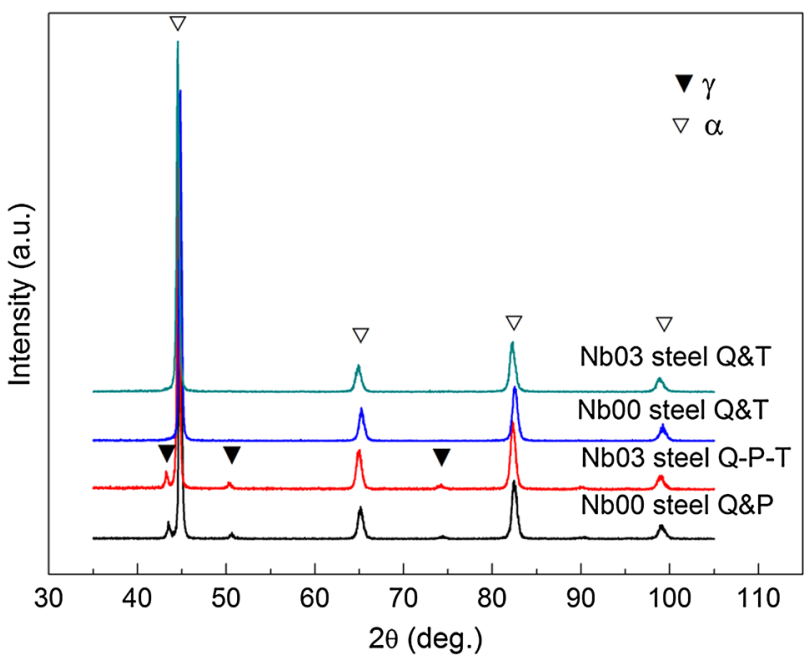

Fig. 3 XRD patterns of the $\mathrm{Nb00}$ steel and $\mathrm{Nb} 03$ steel treated by $Q-$ $P-T, Q \& P$ and $Q \& T$ processes images (Fig. 4b, d). The inserted selected area electron diffraction (SAED) patterns indicate that the orientation relationships between martensite and retained austenite are $(\overline{1} \overline{1} 0)_{\alpha} / /(\overline{1} \overline{1} 1)_{\gamma}$ and $[001]_{\alpha} / /[011]_{\gamma} \mathrm{N}-\mathrm{W}$ orientation relationship (Fig. 4b). There is a coexistence of $\mathrm{N}-\mathrm{W}$ and $\mathrm{K}-\mathrm{S}$ orientation relationship, i.e., $(\overline{1} \overline{1} 0)_{\alpha} / /(\overline{1} \overline{1} 1)_{\gamma}$ and $[\overline{1} 11]_{\alpha} / /$ $[011]_{\gamma}$ (Fig. 4d). It is worth noting that TEM images exhibit film-like retained austenite in Q\&T specimen. But, retained austenite could not be detected in XRD spectrum (Fig. 3), indicating that the volume fraction of retained austenite in Q\&T sample is too less to be determined. Figure 5 shows the TEM micrographs of the Nb03 steel treated by Q\&T and $\mathrm{Q} \& \mathrm{P}$ processes. It can be seen from Fig. $5 \mathrm{~b}$, d that there are large numbers of fine spherical precipitated carbides with average particle size about 5-10 nm dispersedly distributed in the martensite matrix. These spherical carbides are identified as $\mathrm{NbC}$ with fcc lattice structure by SAED inserted in Fig. 5b. Moreover, the $\mathrm{NbC}$ carbides and martensite matrix take Bake-Nutting $(\mathrm{B}-\mathrm{N})$ orientation relationship as $(01 \overline{1})_{\alpha} / /(\overline{2} 00)_{\mathrm{NbC}}$ and $[011]_{\alpha} / /[0 \overline{1} \overline{1}]_{\mathrm{NbC}}$.

\section{Discussion}

\subsection{Effects of Nb on Strength and Ductility}

By comparing $\mathrm{Nb}$-microalloyed steels with $\mathrm{Nb}$-free steels, we can find that the $\mathrm{Nb}$-microalloyed steels have higher strength, and the increment of yield strength is more obvious in $\mathrm{Nb}$-microalloyed steels compared to the samples without $\mathrm{Nb}$. For instance, the $\sigma_{0.2}$ of Nb03 Q\&T steel was increased by $78 \mathrm{MPa}$ as compared to that of $\mathrm{Nb00}$ Q\&T steel, while $\sigma_{\mathrm{b}}$ was increased by $71 \mathrm{MPa}$. In particular, the $\sigma_{0.2}$ of Nb03 Q$\mathrm{P}-\mathrm{T}$ steel was increased by $52 \mathrm{MPa}$ when compared with that of $\mathrm{Nb00}$ Q\&P steel, while the $\sigma_{\mathrm{b}}$ was increased only by $11 \mathrm{MPa}$. It is well known that the increase in yield strength depends on grain refinement according to Hall-Petch relation [29]. The increase in tensile strength depends on the size, amount and distribution of spherical carbides in matrix based on Zener equation [30] and grain size as well. Therefore, it is reasonable to believe that the grain refinement strengthening of $\mathrm{Nb}$ is stronger than its precipitation strengthening. In the previous investigation [31], precipitation temperature of $\mathrm{Nb}$ is about $1200{ }^{\circ} \mathrm{C}$ and thus the 

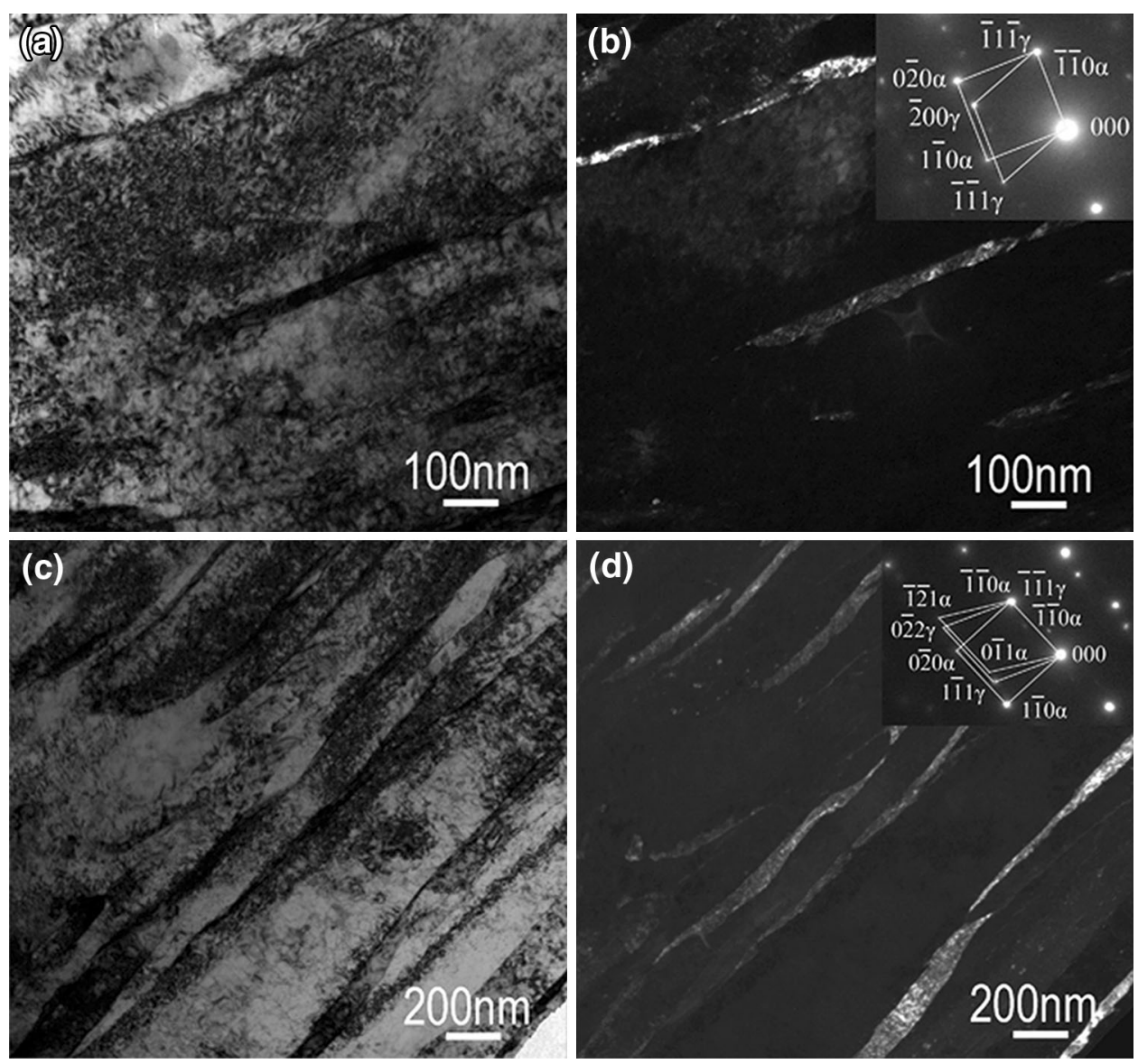

Fig. 4 TEM micrographs of the Nb00 steel treated by Q\&T and Q\&P processes, respectively: a Q\&T, bright-field image; b Q\&T, dark-field image and $\overline{1} \overline{1} 1_{\gamma}$ and $1 \overline{1} 1_{\gamma}$ diffraction spots of retained austenite; c Q\&P, bright-field images; d Q\&P, dark-field image and $\overline{1} 11_{\gamma}$ and $1 \overline{1} 1_{\gamma}$ diffraction spots of retained austenite

pinning effect of $\mathrm{Nb}$ on grain boundaries results in refinement of austenite grain during hot-rolling. During subsequent austenitizing, the pinning effect of $\mathrm{Nb}$ on grain boundaries results in further refinement of austenite grain. The refinement of austenite grains gives rise to the decrease in martensite packet and block sizes [32]. This is the reason that $\mathrm{Nb}$ can markedly enhance the yield strength of steel. The Nb-carbides precipitate during austenitizing and partitioning/tempering, respectively, in which $\mathrm{Nb}$-carbides have larger size during austenitizing, about several tens nanometer, and $\mathrm{Nb}$-carbides have smaller size, about several nanometer [33]. As a result, the tensile strength increase is mainly attributed to fine $\mathrm{Nb}$-carbides precipitated from martensite matrix during partitioning/tempering. The strengthening effect from the precipitation of carbides will always cause the loss of ductility because they impede the movement of dislocations [34]. However, the refinement of grains will possibly lead to of ductility increase. Because the grain boundaries impede the movement of dislocations, and smaller grains accompanying with more grain boundaries, which will result in the ductility decrease. In other hand, the refinement of grains increases the ductility based on effect of grain size on Lüders elongation [35]. Therefore, it is reasonably concluded that the effect of $\mathrm{Nb}$ on ductility by grain refinement compensates impeding effect of $\mathrm{Nb}$-carbides on dislocation movement in this work, and thus the elongation of $\mathrm{Nb}$-microalloyed steels is slightly higher than that of $\mathrm{Nb}$ free steels. It is worth noting that low- and medium-carbon martensitic steels $(<0.5 \mathrm{wt} \%)$ may have tempering brittleness when they were tempered between 300 and $500{ }^{\circ} \mathrm{C}$ due to precipitation of brittle phase $\mathrm{Fe}_{3} \mathrm{C}$ carbides [36]. However, the addition of $\mathrm{Si}$ element can suppress the precipitation of the brittle $\mathrm{Fe}_{3} \mathrm{C}$ carbides [37]. So, in designing $\mathrm{Fe}-$ Mn-Si-based Q-P-T steel, stable NbC carbides precipitate from martensite matrix and no formation of brittle $\mathrm{Fe}_{3} \mathrm{C}$ carbides during tempering of $450{ }^{\circ} \mathrm{C}$. Thus, tempering brittleness will be avoided and the ductility of Q-P-T steel increased. 

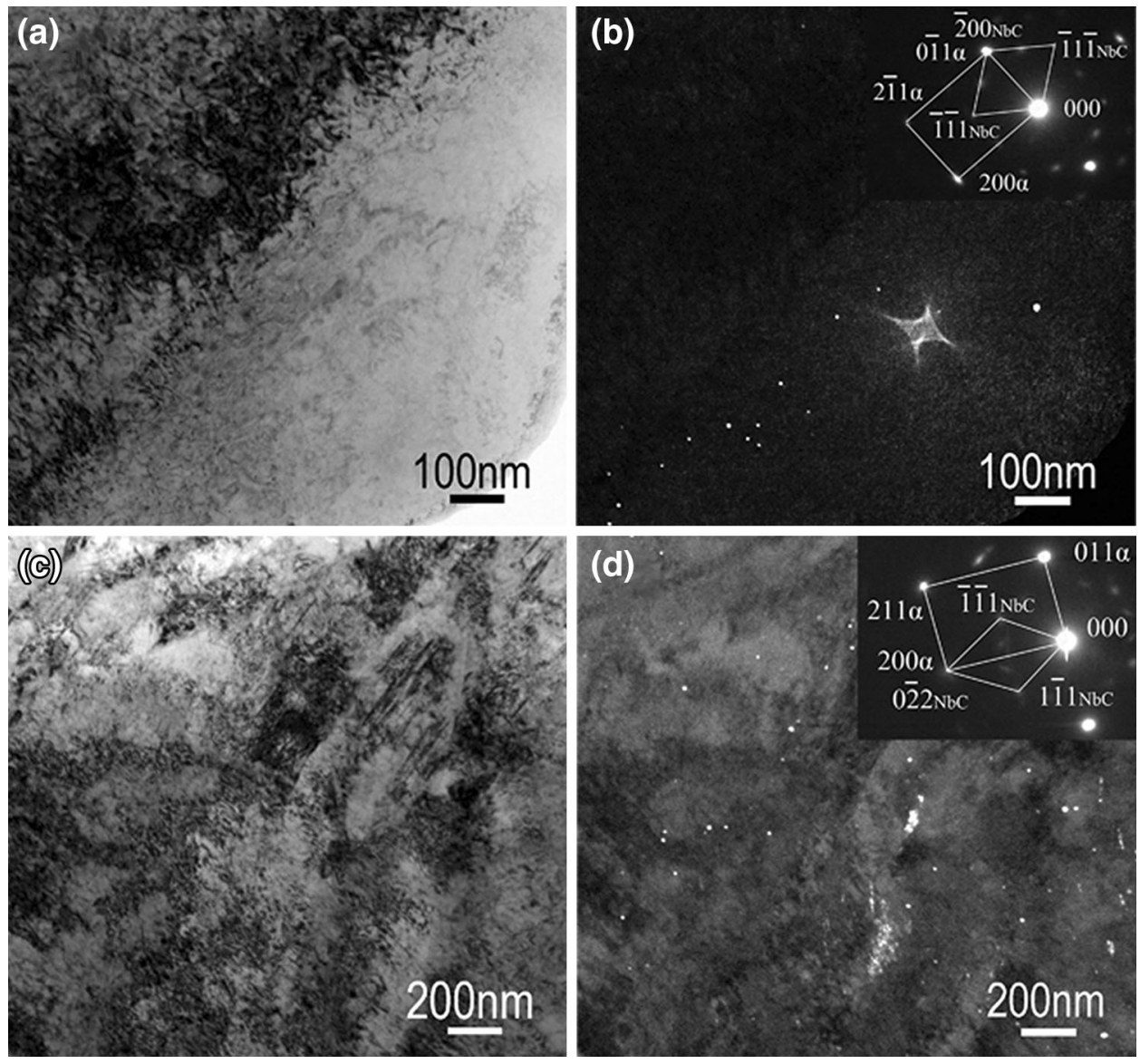

Fig. 5 TEM micrographs of the Nb03 steel treated by Q\&T and Q\&P processes: a Q\&T, bright-field image; b Q\&T, dark-field image and $11 \overline{1}_{\mathrm{NbC}}$ diffraction spots of retained austenite; c Q\&P, bright-field images; d Q\&P, dark-field image and $11 \overline{1}_{\mathrm{NbC}}$ diffraction spots of retained austenite

\subsection{Mechanism for Ductility Enhancement in Q-P-T Process}

As mentioned above, Q-P-T process contains the essentials of the $\mathrm{Q} \& \mathrm{P}$ process. Quenching temperature $\left(T_{\mathrm{q}}\right)$ is determined by both CCE theory and $\mathrm{K}-\mathrm{M}$ equation, where the $T_{\mathrm{q}}$ is usually much higher than room temperature for low and medium steel. And thus, the Q-P-T martensitic steels have considerable retained austenite comparing with the traditional Q\&T steels. The origin of retained austenite on ductility enhancement results from three effects: DARA effect, TRIP effect and BCP effect. The DARA effect makes the hard phase, martensite, maintain in a "softening" state during whole deformation and availably intensifies the deformation ability of the hard phase, martensite, at uniform deformation stage, and in turn evidently improves the ductility. Since not every martensite grain (lath) would have an adjacent retained austenite, only the dislocations in martensite lath neighboring retained austenite can move into the retained austenite. Meanwhile, $\mathrm{Lu}$ et al. [38] experimentally reported that the dislocation cannot form in the retained austenite with the thickness less than $15 \mathrm{~nm}$. As a result, the more the retained austenite is, the stronger the DARA effect is. With further increase in strain, the strain-induced martensitic transformation from retained austenite will occur when the stress in local area of retained austenite reaches certain critical value, and this leads to the well-known TRIP effect because strain-induced martensitic transformation relaxes the stress concentration in this area and avoids the formation of cracks effectively, and thus delays the necking of the Q-P-T steel. Obviously, the more the retained austenite is, the stronger the TRIP effect is. Under subsequent larger strain condition, once cracks form and propagate in some high stress concentration areas, the retained austenite can block further the propagation of cracks, i.e., BCP effect occurs. The BCP effect effectively postpones the fracture of sample and increases the total elongation of martensitic steels. In addition to ductility enhancement stemming from considerable retained austenite by Q-P-T process, we find that higher $T_{\mathrm{q}}$ can effectively decrease thermal stress and phase-transformation stress. It can be qualitatively 

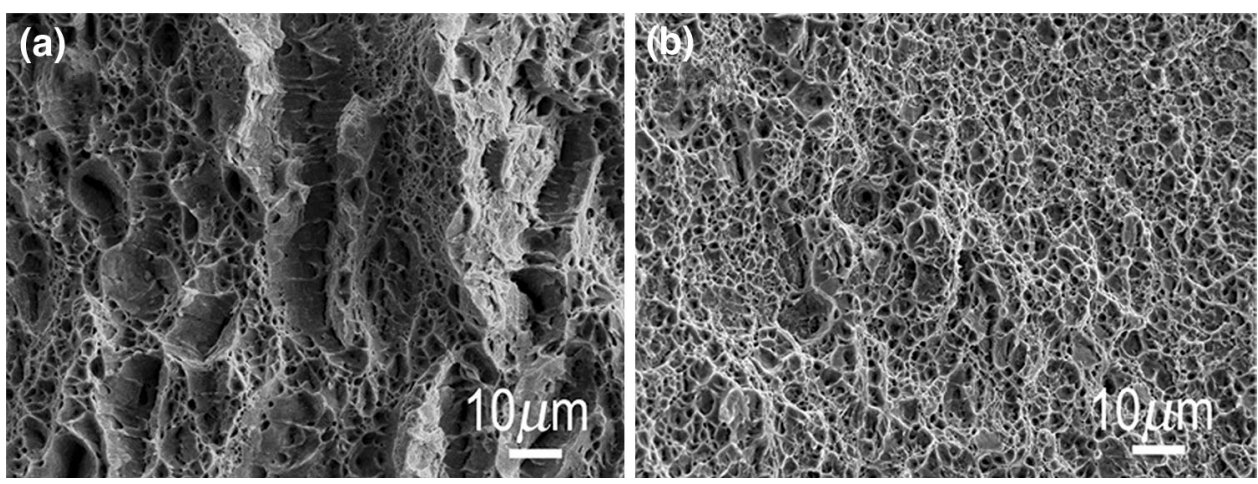

Fig. 6 SEM fractographs of the Nb03 steel treated by Q\&T a, Q-P-T b processes

analyzed by the relationship between stress $\sigma$ and temperature as follows [39]:

$\sigma=\alpha_{1} E\left(T_{0}-T_{\mathrm{f}}\right)$.

where $E$ and $\alpha_{1}$ are the elastic modulus and the coefficient of thermal expansion, respectively, and they are constant for a given material; $T_{0}$ and $T_{\mathrm{f}}$ are initial and final temperature, respectively. In the present case, $T_{0}=940{ }^{\circ} \mathrm{C}$ and $T_{\mathrm{f}}=20^{\circ} \mathrm{C}$ (room temperature) for Q\&T process and $300{ }^{\circ} \mathrm{C}$ is for $\mathrm{Q}-\mathrm{P}-\mathrm{T}$ (or $\mathrm{Q} \& \mathrm{P}$ ) process, respectively. Obviously, the thermal stress caused by Q\&T process is much higher than that by Q-P-T (or Q\&P) one at quenching stage. In addition, we can know from $\mathrm{K}-\mathrm{M}$ equation [12] that the $T_{\mathrm{q}}$ in $\mathrm{Q} \& \mathrm{~T}$ process is much lower than that in Q-P-T process, and more transformation from austenite to martensite occurs in Q\&T process, which will probably cause the initiation of microcracks. Figure 6 shows the SEM images of fracture morphologies of $\mathrm{Nb} 03$ Q\&T and Q-P-T samples, respectively. They have the same composition, but the $T_{\mathrm{q}}$ in $\mathrm{Q} \& \mathrm{~T}$ process is much lower than that in Q-P-T process. It can be seen that the number of the secondary microcracks in Q\&T fracture sample (Fig. 6a) is more and the size is larger than that in Q-P-T fracture sample (Fig. 6b), which can be attributed to higher thermal stress and transformation stress caused by Q\&T process. By comparison of the fracture morphologies of Q-P-T sample with Q\&T sample (see Fig. 6), the tearing ridges in $\mathrm{Q}-\mathrm{P}-\mathrm{T}$ sample are more than those in Q\&T sample, which probably results from much softer phase, the retained austenite. The dimples in Q-P-T sample are deeper and more uniform than those in Q\&T sample, which probably results from lower dislocation density in martensite matrix in Q-P-T sample. Partitioning of carbon from martensite to retained austenite results in relative low dislocation density in martensite, and the dislocation density in martensite will further decrease due to DARA effect during deformation.

\section{Conclusions}

1. The addition of $\mathrm{Nb}$ to $\mathrm{Fe}-\mathrm{Mn}-\mathrm{Si}$-based steels markedly raises the strength, especially the yield strength. The yield strength of Nb-microalloyed Q\&T steel was increased by $78 \mathrm{MPa}$ when compared with that of $\mathrm{Nb}$ free Q\&T steel, while that of Nb-microalloyed Q-P-T steel was increased by $52 \mathrm{MPa}$ when compared with that of $\mathrm{Nb}$-free Q\&P steel under the same heat treatment condition. The elongation of Nb-microalloyed steels is slightly higher than that of $\mathrm{Nb}$-free steels.

2. The mechanism for ductility enhancement in Q-P-T process is resulted from both considerable amount of retained austenite and high quenching temperature $T_{\mathrm{q}}$ leading to lower thermal inner stress.

3. In the designed the Fe-Mn-Si-based Q-P-T steel, stable $\mathrm{NbC}$ carbides precipitate in the martensite matrix and no brittle $\mathrm{Fe}_{3} \mathrm{C}$ carbides form during $450{ }^{\circ} \mathrm{C}$ tempering. Tempering brittleness is avoided by addition of $\mathrm{Si}$, and the ductility of Q-P-T steel is thus increased.

Acknowledgments The work was financially supported by the National Natural Science Foundation of China (No. 51301106).

\section{References}

[1] J. Van Slycken, P. Verleysen, J. Degrieck, J. Bouquerel, B.C. De Cooman, Mater. Sci. Eng., A 460-461, 516 (2007)

[2] Y.I. Son, Y.K. Lee, K.T. Park, C.S. Lee, D.H. Shin, Acta Mater. 53, 3125 (2005)

[3] B.C. De Cooman, Curr. Opin. Solid State Mater. Sci. 8, 285 (2004)

[4] J. Shi, X. Sun, M. Wang, W. Hui, H. Dong, W. Cao, Scr. Mater. 63, $815(2010)$

[5] J.G. Speer, D.K. Matlock, B.C. De Cooman, J.G. Schroth, Acta Mater. 51, 2611 (2003)

[6] J.G. Speer, D.V. Edmonds, F.C. Rizzo, D.K. Matlock, Curr. Opin. Solid State Mater. Sci. 8, 219 (2004) 
[7] J.G. Speer, D.K. Matlock, B.C. De Cooman, J.G. Schroth, Scr. Mater. 52, 83 (2005)

[8] D.V. Edmonds, K. He, F.C. Rizzo, B.C. De Cooman, D.K. Matlock, J.G. Speer, Mater. Sci. Eng., A 438-440, 25 (2006)

[9] A.J. Clarke, J.G. Speer, M.K. Miller, R.E. Hackenberg, D.V. Edmonds, D.K. Matlock, Acta Mater. 56, 16 (2008)

[10] T.Y. Hsu, Mater. Sci. Forum 561-565, 2283 (2007)

[11] X.D. Wang, B.X. Huang, L. Wang, Y.H. Rong, Metall. Mater. Trans. A 39, 1 (2008)

[12] D.P. Koistinen, R.E. Marburger, Acta Metall. 7, 59 (1959)

[13] X.D. Wang, N. Zhong, Y.H. Rong, T.Y. Hsu, J. Mater. Res. 24, 260 (2009)

[14] K. Zhang, W.Z. Xu, Z.H. Guo, Y.H. Rong, M.Q. Wang, H. Dong, Acta Metall. Sin. 47, 489 (2011). (in Chinese)

[15] N. Zhong, X.D. Wang, L. Wang, Y.H. Rong, Mater. Sci. Eng., A 506, 111 (2009)

[16] V.F. Zackay, E.R. Parker, D. Fahr, R. Busch, ASM Trans. Q. 60, 252 (1967)

[17] R. Feng, M.H. Zhang, N.L. Chen, X.W. Zuo, Y.H. Rong, Acta Metall. Sin. 50, 498 (2014). (in Chinese)

[18] D. Webster, ASM Trans. Q. 61, 816 (1968)

[19] R. Ayer, P.M. Machmeier, Metall. Trans. A 24, 1943 (1993)

[20] C.C. Wang, C. Zhang, Z.G. Yang, Micron 67, 112 (2014)

[21] K. Zhang, M.H. Zhang, Z.H. Guo, N.L. Chen, Y.H. Rong, Mater. Sci. Eng., A 528, 8486 (2011)

[22] S. Shao, S.N. Medyanik, Modell. Simul. Mater. Sci. Eng. 18, 055010 (2010)

[23] Y.H. Rong, Int. Heat Treat. Surf. Eng. 5, 145 (2011)

[24] Y. Wang, K. Zhang, Z.H. Guo, N.L. Chen, Y.H. Rong, Mater. Sci. Eng., A 552, 288 (2012)
[25] S.W. Qin, Y. Liu, Q.G. Hao, Y. Wang, N.L. Chen, X.W. Zuo, Y.H. Rong, Metall. Mater. Trans. A 46, 1 (2015)

[26] Q.G. Hao, Y. Wang, X.S. Jia, X.W. Zuo, N.L. Chen, Y.H. Rong, Acta Metall. Sin. (Engl. Lett.) 27, 444 (2014)

[27] S. Zhou, K. Zhang, Y. Wang, J.F. Gu, Y.H. Rong, Metall. Mater. Trans. A 43, 1026 (2012)

[28] R.O. Ritchie, Nat. Mater. 10, 817 (2011)

[29] C.F. Wang, M.Q. Wang, J. Shi, W.J. Hui, H. Dong, J. Mater. Sci. Technol. 23, 659 (2007)

[30] P.A. Manohar, M. Ferry, T. Chandra, ISIJ Int. 38, 913 (1998)

[31] X.D. Wang, B.X. Huang, Y.H. Rong, L. Wang, in Proceedings of 3rd International Conference on Advanced Structural Steels (ICASS, Gyeongju, Korea, 2006), p. 1152

[32] S. Morito, X. Huang, T. Furuhara, T. Maki, N. Hansen, Acta Mater. 54, 5323 (2006)

[33] X.D. Wang, W.Z. Xu, Z.H. Guo, L. Wang, Y.H. Rong, Mater. Sci. Eng., A 527, 3373 (2010)

[34] K. Lu, L. Lu, S. Suresh, Science 324, 349 (2009)

[35] X.L. Li, Z.H. Guo, Y.H. Rong, H.Y. Wu, S.F. Wu, Acta Metall. Sin. 50, 439 (2014). (in Chinese)

[36] C.L. Briant, Mater. Sci. Technol. 5, 138 (1989)

[37] S.S. Nayak, R. Anumolu, R.D.K. Misra, K.H. Kim, D.L. Lee, Mater. Sci. Eng., A 498, 442 (2008)

[38] L. Lu, M.L. Sui, K. Lu, Science 287, 1463 (2000)

[39] W.D. Callister Jr, Materials science and engineering: an introduction, 2nd edn. (Wiley, New York, 1985), p. 306 